\title{
ALTERNATIVA DA CAPTAÇÃO DE ÁGUA DA CHUVA: QUALIDADE DA ÁGUA ARMAZENADA EM CISTERNAS E EM TANQUES NATURAIS
}

\author{
ALTERNATIVE OF RAINWATER CATCHMENT'S: WATER QUALITY STORED IN CISTERNS AND STONES TANKS
}

\section{RESUMO}

A baixa quantidade de chuva associada à elevada irregularidade espacial e temporal no semiárido paraibano são as principais responsáveis pela insegurança hídrica. Diante disto, procurou-se estimar o potencial de captação de água da chuva e a qualidade da água armazenada nos tanques naturais, no Sítio Olho d'água, Pocinhos, PB, e nas cisternas, na zona rural de Barra de São Miguel, sendo essas determinações os objetivos principais. Séries pluviais mensais das respectivas localidades, cedidas pela Agência Executiva de Gestão das Águas da Paraíba, foram analisadas usando-se critérios da estatística climatológica, sendo estabelecidos o regime pluvial e os volumes de captação de água da chuva. As análises da qualidade da água nos tanques naturais e cisternas foram estabelecidas de acordo com a Portaria no 518/04 do Ministério da Saúde. Os principais resultados indicaram que o regime pluvial é irregular, assimétrico e o potencial de captação de água da chuva é a principal alternativa hídrica para o semiárido nordestino. Os indicadores de qualidade da água armazenadas nos tanques de pedras e nas cisternas foram maiores que os valores estabelecidos pela Portaria do Mistério da Saúde e, portanto, não são potáveis. Além disso, a maioria da água (das cisternas) está contaminada com bactérias heterotróficas.

Palavras-chave: clima, segurança hídrica, tanques de pedra e cisterna.

\section{ABSTRACT}

Low rainfall associated with high spatial and temporal irregularity in the semiarid Paraiba is mainly responsible for water insecurity. Before this, we tried to estimate the potential of rainwater catchment's and the quality of stored water in the natural tanks, the site Olho d'água, Pocinhos, PB, and in the cisterns, in the rural zone of Barra de São Miguel, being those determinations the main objectives. Monthly rainfall series of the respective places, given in by the Executive Agency of Administration of the Waters of Paraiba, were analyzed using statistical climatologically criteria, established the rainfall patterns and volumes of rain water catchment's. The water quality analyses on cisterns and tanks stones were established in agreement with the Entrance n-518/04 of ministry of Health. The main results indicated that rainfall patterns is irregular, asymmetrical and the potential of rainwater catchment's is the main water alternative to the semi-arid Northeastern. The indicators of quality of the water stored in the tanks of stones and in the cisterns they were larger than the established values for the Entrance of the Mystery of the Health and, therefore, they are not drinkable. Furthermore, most of the water (of the cisterns) is contaminated with heterotrophic bacteria.
Hermes Alves de Almeida ${ }^{a}$ Crislânne Lemos Viriato ${ }^{a}$

Erandi Andrade de Moura Sampaio ${ }^{\text {a }}$

${ }^{\text {a }}$ Universidade Estadual da Paraíba (UEPB), Imperatriz, MA, Brasil

DOI: 10.12957/geouerj.2020.36106

Correpondência:

hermes_almeida@uol.com.br

Recebido em: 17 jul. 2018 Aceito em: 6 out. 2020

Keywords: climate, water security, stone tanks and cistern. 


\section{INTRODUÇÃO}

A água é um recurso natural indispensável à sobrevivência do homem e dos demais seres vivos deste Planeta. Constata-se, entretanto, que a baixa disponibilidade hídrica é para muitas regiões e/ou locais o principal fator limitante ao desenvolvimento.

As migrações de famílias ou de alguns dos seus membros, no semiárido nordestino, são claramente associadas às estiagens, que as obrigam a deixarem as suas terras. Mesmo com os avanços no processo de gerenciamento de recursos hídricos no Brasil, há desafios tanto no âmbito de gestões da água quanto aos dos riscos climáticos.

A captação de água de chuva tem-se revelado uma alternativa viável e importante para o semiárido, por aumentar a disponibilidade de água (ALMEIDA, MOURA e FARIAS, 2017). Embora o quantitativo seja importante, não se pode esquecer o aspecto qualidade, representado por um conjunto de características físicas, químicas e biológicas relacionado à saúde humana (BRITO et al., 2007).

A qualidade da água de chuva captada em telhados é, geralmente, mais limpa que a dos rios. Além disso, os processos de decantação, flotação, dentre outros fazem com que a água armazenada em cisternas seja mais limpa. Assim sendo, o risco de contrair doença ao consumir essa água, mesmo não tratada, é provavelmente menor que a superficial não tratada (SINCLAIR et al., 2005).

De acordo com a legislação brasileira, toda a água destinada ao consumo humano deve obedecer ao padrão de potabilidade e estar sujeita à vigilância da sua qualidade (BRASIL, 2004). No entanto, à carência de conhecimento científico sobre a qualidade da água captada nos telhados é comum achar que seja uma fonte segura, até mesmo, para o consumo humano (LYE, 2009).

Tem-se procurado melhorar a qualidade da água captada e armazenada em cisternas, utilizando-se barreiras sanitárias que visam eliminar microrganismos patogênicos e/ou organismos indesejáveis para o interior da cisterna.

Em avaliações da qualidade da água captada e sem descarte, armazenada na maioria das cisternas de comunidades rurais do semiárido paraibano (TAVARES, 2009; XAVIER, 2010 e ALMEIDA e VIRIATO, 2014) encontraram contaminação fecal, presença de coliformes totais, E.coli e bactérias heterotróficas totais, na água usada no consumo humano.

Com o uso de dispositivos de descarte automático das primeiras águas da chuva, como barreiras sanitárias, SOUZA et al., (2011) não encontraram contaminação por $E$. coli em nenhuma parte do sistema, o que reforça a tese que a $E$. coli em cisternas provem do manejo inadequado do usuário.

Os padrões de qualidade da água variam em função do uso. Para consumo humano, a água deve obedecer a Portaria no 518, de 25 de março de 2004, do Ministério da Saúde (BRASIL, 2004), que estabelece: "água potável é 
aquela cujos parâmetros microbiológicos, físicos, químicos e radioativos atendem ao padrão de potabilidade e não oferece risco à saúde".

A definição de qualidade da água vai muito mais além do que a sua simples caracterização de sua fórmula molecular $\mathrm{H}_{2} \mathrm{O}$, mas sim do seu relacionamento com os seus múltiplos usos, que resulta de fenômenos naturais ou antrópicas (VON SPERLING, 2005). A água para ser saudável, não pode conter substâncias tóxicas, vírus, bactérias ou mesmo parasitas, e quando não tratada devidamente torna-se um dos maiores veículos de transmissão de doenças (BRASILEIRO, 2009).

A maior parte do território paraibano é constituída por rochas resistentes, muito antigas, que formam o complexo cristalino da era pré-cambriana. Nessas estruturas geomorfológicas, as reservas de águas subterrâneas são, naturalmente, limitadas.

A captação de água da chuva é uma alternativa hídrica viável e secular em diversas partes do mundo. As tecnologias de captação e manejo de água de chuva costumam ser chamadas e/ou conhecidas como "tecnologias sócias" (GNADLINGER, 2006). Elas existem em vários locais, mas, por serem extremamente simples, nem sempre o status de tecnologia lhes é facilmente conferida (LASSANCE JUNIOR e PEDREIRA, 2004).

O uso de Tanques Naturais para captar e armazenar água no semiárido brasileiro remonta ao Século XIX (BRAGA, 1962). Essas estruturas têm essas denominações, embora sejam também nomeadas de caldeirões, por exemplo, e resultam de depressões de dimensões e formas variadas, fendas largas, barrocas ou buracos naturais.

Os referidos tanques acumulam águas pluviais na parte não preenchida pelos sedimentos e constituem uma das fontes mais utilizadas ao longo dos séculos, tanto pela população humana como pelos animais domésticos (XIMENES, 2013).

A captação de água da chuva, nesses reservatórios naturais, tem-se revelado uma tecnologia importante de convivência com o semiárido nordestino.

Diante deste contexto, houve necessidade de se estimar o potencial de captação de água da chuva e analisar a qualidade das águas armazenada nos tanques naturais e nas cisternas, localizadas, respectivamente, nos Sítios Olho D’Água, Pocinhos, PB, e Floresta, Barra de São Miguel, sendo essas determinações os objetivos principais deste trabalho.

\section{MATERIAL E MÉTODOS}

A área de estudo foi constituída por sete (07) Tanques Naturais (pedras), localizados no Sítio Olho D’água, localizados no município de Pocinhos, PB (Figura 1), latitude 707'54”S, longitude 360 06’34”W e altitude 650 m, 
microrregião geográfica do Curimataú Ocidental da Paraíba e doze (12) cisternas, localizadas zona rural do município de Barra de São Miguel (7ㅇ3' S, longitude de 3614' W e altitude 398 m), na microrregião do Cariri paraibano (Figura 1).

Figura 1. Mapa geográfico do Estado da Paraíba, com destaque para os municípios de Pocinhos e Barra de São Miguel.

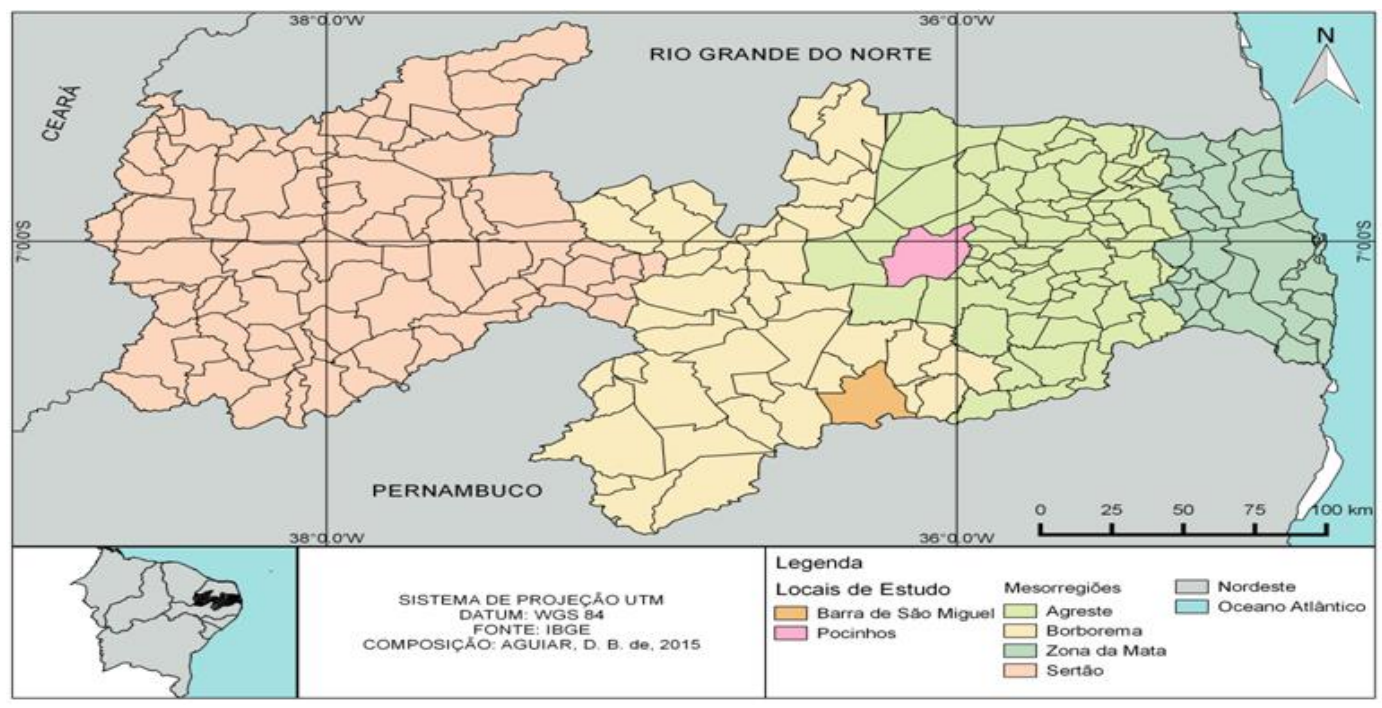

Os dados de precipitação pluvial- mensais e anuais- das localidades de Pocinhos, PB, e Barra de Santana foram cedidos pela Agência Executiva de Gestão das Águas do Estado da Paraíba, AESA, Campina Grande, PB.

Foram estabelecidos seis cenários de regime pluvial anual, correspondentes aos os níveis de 25,50 e 75 \% de probabilidade, os totais referentes ao ano mais seco, o mais chuvoso e o mediano da série pluvial. Maiores detalhes metodológicos das análises estatísticas e/ou de critérios são encontrados nos artigos de ALMEIDA, FREITAS e SILVA (2013); ALMEIDA e CABRALJÚNIOR (2014).

Para as áreas de captação (cobertura) dos telhados e/ou dos tanques naturais (Ac, em $\mathrm{m}^{2}$ ) e coeficiente de escoamento (Ce, adimensional) foram calculados os volumes potenciais de captação de água da chuva (VPC) mediante a expressão:

$\operatorname{VPC}($ Litros $)=\operatorname{chuva}(\mathrm{mm}) * \mathrm{Ac}\left(\mathrm{m}^{2}\right) * \mathrm{Ce}$

Para analisar a qualidade da água armazenada, nos sete tanques naturais, amostras da água foram coletadas nas margens e no centro, acomodados e etiquetados em recipientes plásticos de $200 \mathrm{ml}$ e encaminhadas ao laboratório da Companhia de Água e Esgoto da Paraíba (CAGEPA), sendo avaliados os parâmetros físico-químicos: cor, turbidez e $\mathrm{pH}$. 
Os valores numéricos de cada um dos respectivos parâmetros foram comparados com os estabelecidos na Portaria do Mistério da Saúde (MS) nำ518/04, para o consumo humano.

A coleta das amostras de água nas doze cisternas foi feita como de costume, ou seja, utilizando-se recipientes como latas de zinco, alumínio e/ou baldes de plástico amarrados com corda.

Os valores dos parâmetros físico-químicos e bacteriológicos utilizados nas análises da qualidade da água das cisternas, para fins de potabilidade, foram comparados com os estabelecidos na Portaria 518/2004 do Ministério da Saúde: pH, Turbidez, Dureza, Alcalinidade Cor, Cloreto, e Bactérias heterotróficas Totais.

A coleta de dados para análises dos parâmetros físico-químicos foi feita usando-se recipientes plásticos do tipo garrafa PET de $500 \mathrm{~mL}$, limpos, esterilizados e fechados. As amostras coletadas eram preservadas numa caixa térmica de isopor com gelo, mantendo-se a uma temperatura inferior a $10^{\circ} \mathrm{C}$, até a chegada ao laboratório de Saneamento Ambiental da Universidade Federal de Campina Grande (UFCG).

Os cálculos, as análises estatísticas e a confecção de gráficos e/ou tabelas foram feitas utilizando-se a Planilha Eletrônica Excel.

\section{RESULTADOS E DISCUSSÃO}

As Figuras 2 e 3 mostram, respectivamente, a distribuição média mensais da media, mediana e desvio padrão da precipitação pluvial das localidades de Pocinhos e Barra de São Miguel. Observa-se que as médias aritméticas mensais da chuva estão sempre associados a uma elevada variabilidade, quantificada pelos respectivos desvios padrão da média (DP). As duas configurações mensais da chuva mostram que os valores dos DPs, de agostosetembro a fevereiro-março, são maiores que os das respectivas médias esperadas. Essa variabilidade na série pluvial demonstra que há uma elevada irregularidade mensal das chuvas das duas localidades.

Figura 2. Distribuição mensal das médias, medianas e desvios padrão da precipitação pluvial. Pocinhos, PB, no período: 1963 a 2017

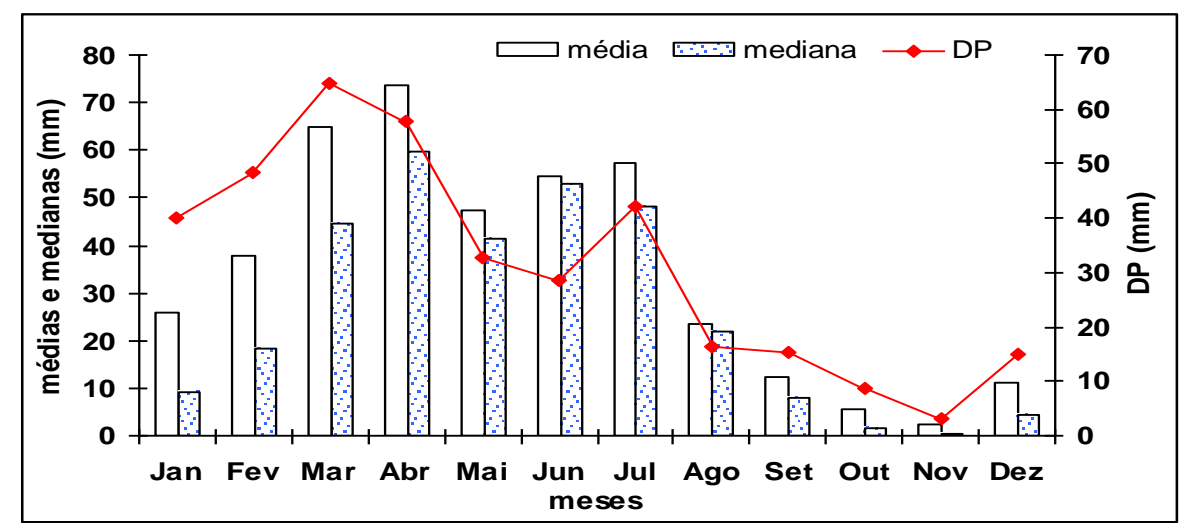


Figura 3. Distribuição mensal das médias, medianas e desvios padrão da precipitação pluvial. Barra de São Miguel, PB, no período: 1963 a 2017

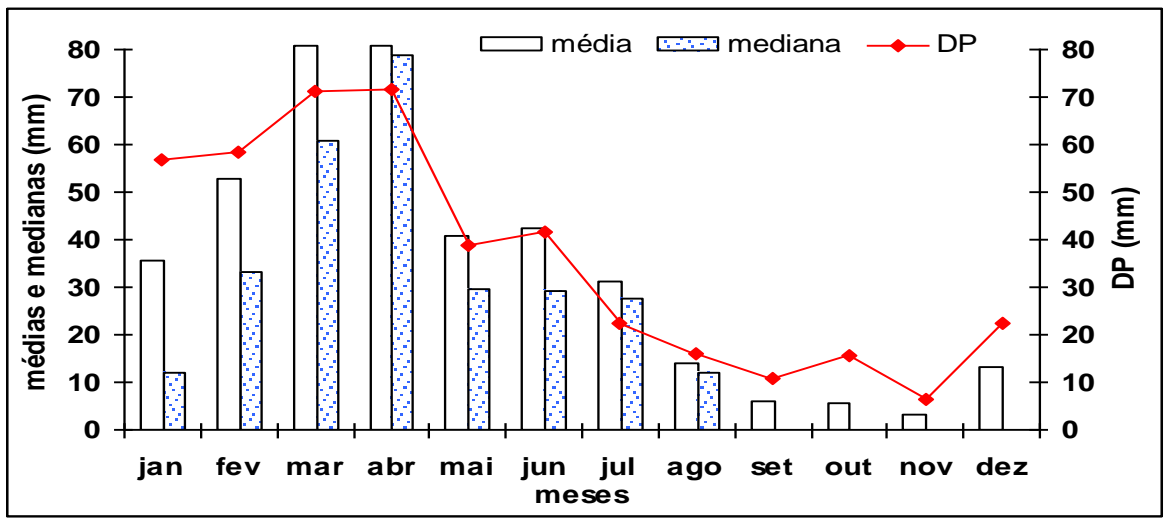

Nota-se, entretanto, que há outra característica importante na distribuição temporal da chuva, que é a desigualdade dos valores das médias com os das medianas, ou seja, com a média sendo sempre maior que a mediana. Por isso, o modelo de distribuição é assimétrico e o coeficiente de assimetria é positivo. Em virtude disto, a mediana passa a ser o valor mais provável de ocorrer e não a média, embora ela seja mais usada.

Esse modelo de assimetria na distribuição mensal de chuvas concorda com o encontrado para outras localidades paraibanas por ALMEIDA e CABRAL (2013) e ALMEIDA, FREITAS e SILVA (2013) ou em outros locais do semiárido nordestino por OLIVEIRA, NÓBREGA e ALMEIDA (2012), que recomendam o uso da mediana, em vez da média.

Os volumes potenciais de captação de água da chuva, para os cinco cenários pré-estabelecidos, são mostrados nas Figuras 4 e 5 .

Figura 4. Volumes potenciais anuais de captação de água da chuva, para cinco cenários pré-estabelecidos. Pocinhos, PB, médias do período de 01.01.1963 a 31.12.2017

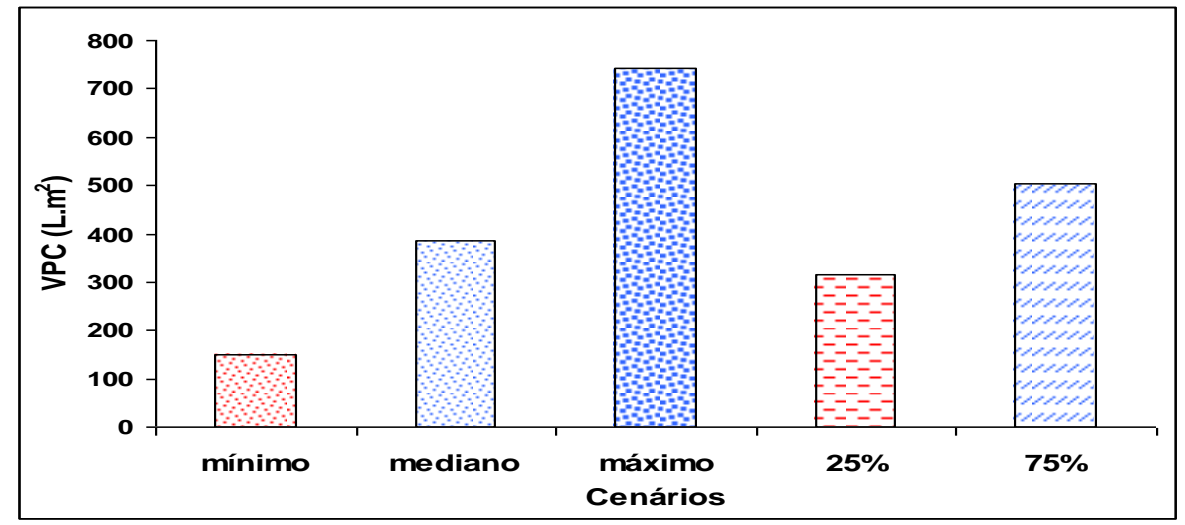


Figura 5. Volumes potenciais anuais de captação de água da chuva, para cinco cenários pré-estabelecidos. Barra de São Miguel, PB, médias do período de 01.01.1963 a 31.12.2017

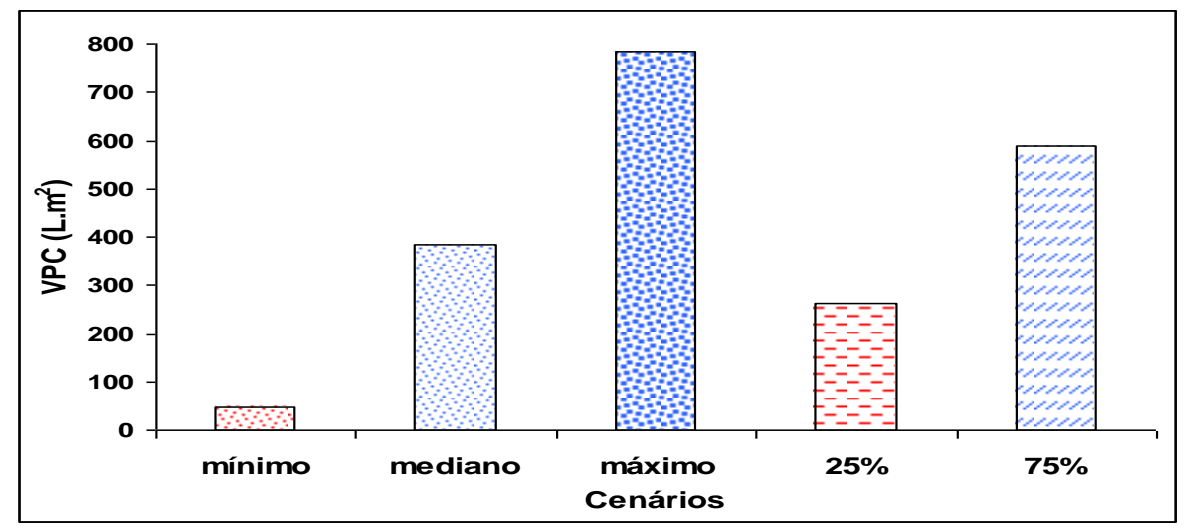

As chances de chover mais de $280 \mathrm{~mm}$ ou menos de $540 \mathrm{~mm}$, por exemplo, são de 25 e 75\%, respectivamente. Já, o valor mediano, de cerca de $380 \mathrm{~mm}$, tem $50 \%$ de probabilidade de ocorrer. Admitindo-se os piores cenários, o ano mais seco (mínimo) e o mais chuvoso (máximo), as chances de se repetir esse quantitativo são pequenas $(<2,0$ \%). Destaca-se, entretanto, que embora as duas localidades distar cerca de $40 \mathrm{~km}$, em linha reta, e pertencerem à microrregião geográfica paraibana distinta, o modelo de distribuição de chuva é muito semelhante.

Os volumes potenciais de captação de água da chuva (VPC), para os cinco cenários de regimes anuais de chuvas, são apresentados, respectivamente, para um dos tanques naturais do Sitio Olho d'água, Pocinhos, PB (Figura 6).

Figura 6. Volume potencial de captação de água da chuva (VPC) no Tanque de Pedra, localizado no Sítio Olho D’Água, Pocinhos, PB, médias do período de 1963 a 2017

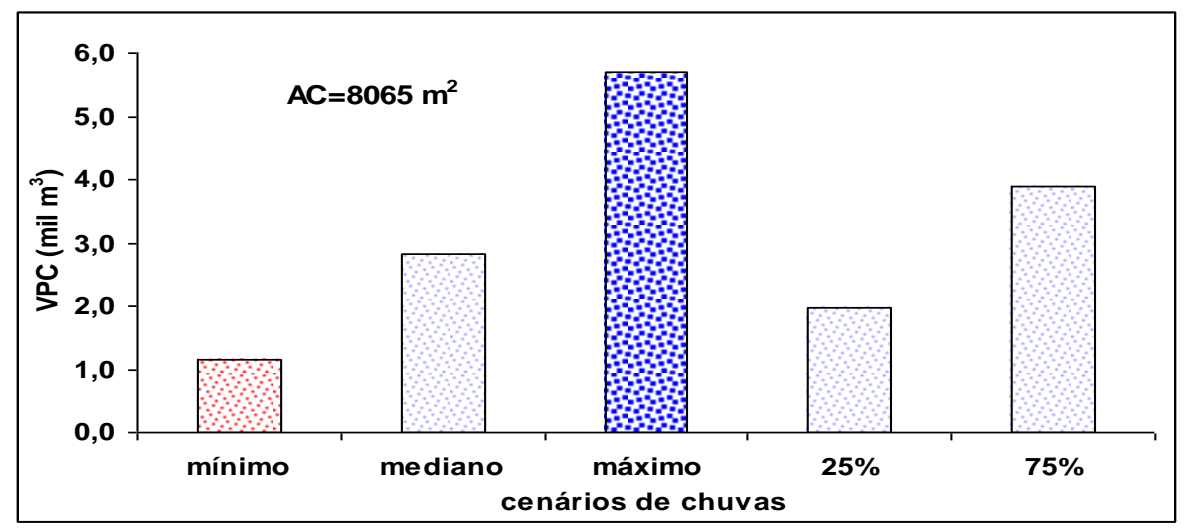

Adotando-se um consumo per capto diário de 50 litros, durante sete meses, a área de interceptação da chuva do referido tanque de pedra captaria uma quantidade (somente para a condição mediana de chuva) suficiente para abastecer uma população de cerca de 270 pessoas, obviamente, bem maior que a residente na zona rural e as que usam água do referido reservatório. 
Mesmo para as duas condições extremas, ou seja, as do ano mais seco e ao nível de 25 \% de probabilidade, a área de captação do tanque de pedra teria um potencial de captar água da chuva para suprir com o mesmo consumo per capto para cerca de 110 e 187 pessoas, respectivamente.

Análise semelhante pode ser feita para as residências em função do tamanho da área de captação. Quando se analisa a condição do cenário mediano da chuva, mesmo para a menor área de captação (casa) com $60 \mathrm{~m}^{2}$, os volumes potenciais superam 16 mil litros. Obviamente, para as casas com áreas de captação maiores, para qualquer outro cenário, inclusive, a do ano mais seco, o potencial de captar é maior que o volume fixo de $16 \mathrm{~m}^{3}$.

É importante destacar que, as cisternas rurais construídas e/ou distribuídas pelos programas do Governo Federal e de outras Instituições têm capacidade para armazenar $16 \mathrm{~m}^{3}$ de água (16 mil litros). No entanto, o volume potencial de captação de água da chuva depende, exclusivamente, do regime pluvial local e do tamanho da área de captação. Já, o consumo da água depende do número de usuário e/ou da finalidade. Assim sendo, não há como fixar um único volume, sem quantificar essas variáveis e, portanto, a "padronização" nem sempre atende as necessidades da família e as cisternas poderão ser sub ou super dimensionadas.

Análise qualitativa da água dos tanques naturais e das cisternas

A referida portaria dispõe sobre os procedimentos de controle e de vigilância da qualidade da água para consumo humano e seu padrão de potabilidade.

As análises da cor da água das amostras colhidas nos sete tanques naturais, do sítio Olho d'água, Pocinhos, PB, nas margens e no centro são mostradas na Figura 7.

Figura 7. Valores da cor da água nas amostras coletadas nos Tanque de Pedras, localizados no Sítio Olho D’Água, Pocinhos, PB, e analisadas pela CAGEPA

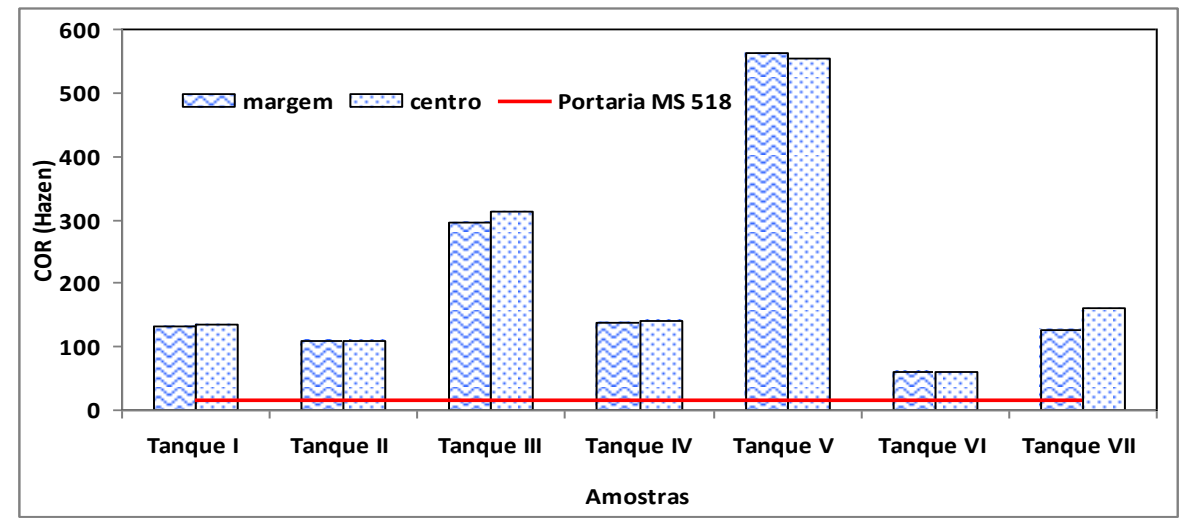


A aparência da água é um dos fatores de satisfação do consumidor. A cor da água é um indicativo da sua qualidade química expressa pela concentração de sólidos dissolvidos. Observa-se (Figura 7) que não há praticamente diferença na cor, quando se compara a da borda com a do centro. Embora os valores tenham sido muito superiores aos estabelecidos na portaria, inclusive acima do limite máximo (15 unidades Hezen, $\mathrm{uH})$.

A água do tanque VI foi a que apresentou menor valor da cor, mesmo assim, bem acima do estabelecido pelo MS. Acredita-se que esses elevados valores se devam a maior presença de materiais sólidos. Essa condição afeta diretamente a turbidez da água, uma vez que diminui a capacidade de absorção da luz, conferindo assim uma aparência turva. As alterações da cor indicam a presença de substâncias orgânicas, oriundas dos processos de decomposição e de alguns íons metálicos, como ferro e manganês e plâncton.

A turbidez é um parâmetro que caracterizar a qualidade da água devido à presença de sólidos em suspensão. Para as mesmas amostras foram analisadas para o parâmetro turbidez, cujos valores são apresentados na Figura 8.

Figura 8. Valores da turbidez nas amostras de água coletadas nos Tanque de Pedras, localizados no Sítio Olho D’Água, Pocinhos, PB, e analisadas pela CAGEPA

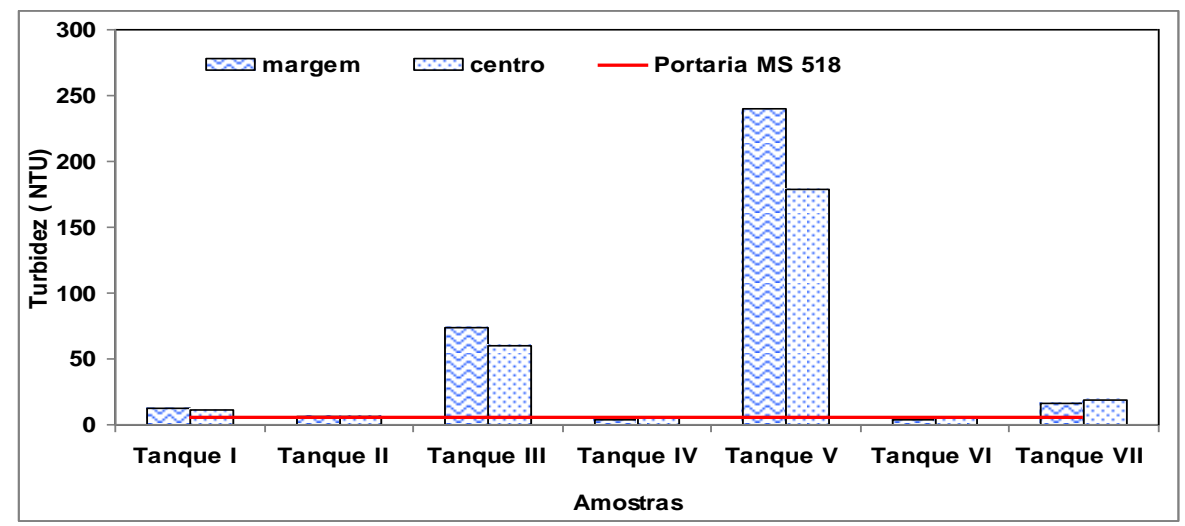

Observa-se que a turbidez da água oscilou entre 3, 98 (Tanque IV) a 240,00 NTU (Tanque V), para as amostras coletadas as margens. Já, para as amostras de água no centro, este parâmetro variou de 4,41 (tanque VI) a 179 NTU (tanque V).

Especificamente as águas dos tanques III e V foram os que apresentaram os maiores índices de turbidez, resultando em uma água com aparência nebulosa, esteticamente indesejável e potencialmente perigosa, segundo os padrões estabelecidos pelo MS

Contudo é possível analisar que as demais águas presentes nos tanques apresentam uma turbidez muito próxima do estabelecido pela MS, que é de 5 NTU, por exemplo, o tanque II, onde a margem apresentou uma turbidez (6,23 NTU) e ao centro (6,52 NTU). Já as águas dos tanques IV e VI têm índices de turbidez menores que os 
estabelecidos pelo MS. Tais diferenças de turbidez se devem à maior ou menor quantidade de materiais sólidos em suspensão, que em algumas situações dificultando a passagem da luz, como cita (HAGEMANN, 2009).

Outro fator que influencia a qualidade da água dos tanques são as fezes de animais depositadas nos afloramentos rochosos. Ao chover há transporte desses dejetos para o interior do tanque, contaminando a água que o impossibilita o consumo sem tratamento.

Diante disto há preocupação da população local, por que a água armazenada nos tanques é a fonte principal ou única da comunidade. Essa condição contribui, em parte, com o texto da CNBB (2004), ao afirmar que 90\% da população rural brasileira não têm acesso a água encanada, o que não significa não ter acesso à água potável.

Com relação ao tratamento da água armazenada nas cisternas, $66,7 \%$ dos entrevistados da zona rural de Barra de São Miguel afirmaram não tratar com cloro, embora após a retirada da água à mesma é filtrada, em filtros de cerâmica.

Esses moradores relataram que não fazem à cloração, porque o uso do cloro deixa a água com sabor desagradável. O restante $(33,3 \%)$ trata a água com produtos à base de cloro (não deixando claro o tipo de produto, nem sua procedência).

A ausência de cloretos na água armazenada nas cisternas analisadas pode ser atrubuído a falta de desinfecção da água desses reservatórios pelos moradores, uma vez que a maioria dos proprietários (66,7\%) não usam cloro e/ou produtos a base de cloro para desinfectar a água da cisterna e argumentam que o sabor da água fica alterado pelo uso de tais produtos.

A Figura 9 apresenta o resumo do número de bactérias heterotrófica, encontradas na água armazenada nas doze cisternas, em UFC/mL.

Figura 9. Número de bactérias heterotróficas na água das cisternas. Sítio Floresta, Barra de São Miguel, PB

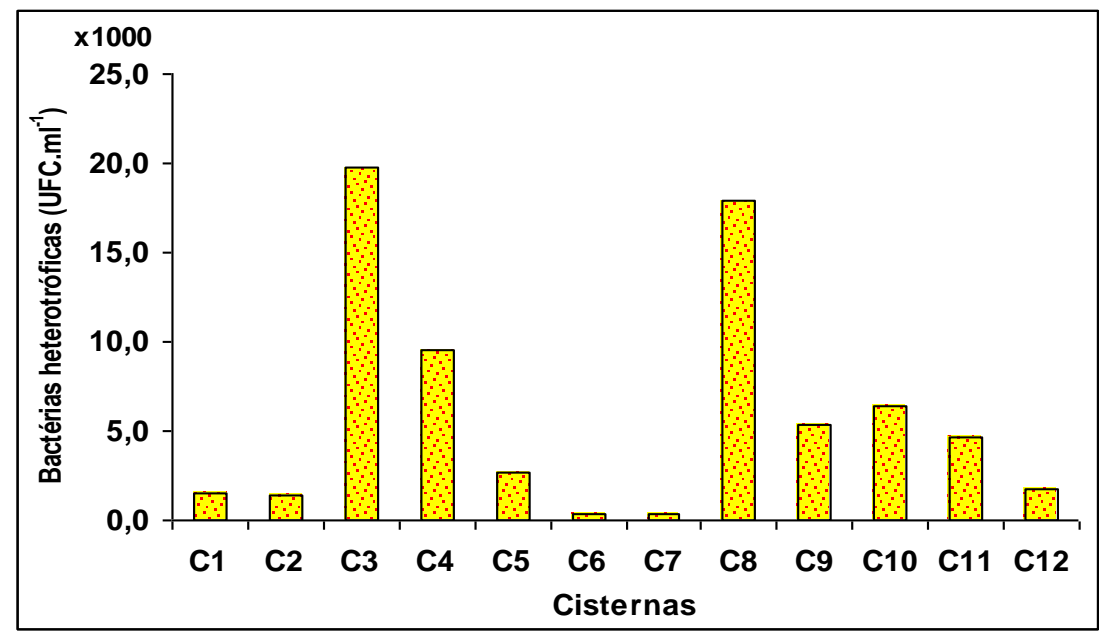


De acordo com os resultados obtidos através das análises laboratoriais, quase todas as amostras, exceto as das cisternas C6 e C7 indicaram presença de bactérias heterotróficas, ou seja, a qualidade da água armazenada nesses sistemas está comprometida pela presença de microrganismos patogênicos ou não.

As bactérias heterotróficas são capazes de proliferar na água, se estiverem disponíveis nutrientes, temperatura adequada, ausência de agente desinfetante residual (cloro) e estagnação da água, a cloração da água de chuva apenas uma vez ao ano, não restando cloro residual no decorrer dos meses, podendo ser considerado como falha na desinfecção; e a baixa adesão à limpeza periódica das cisternas, mantendo os sedimentos no fundo da cisterna. Por apresentar características favoráveis à proliferação de bactérias heterotróficas (presença de nutrientes, ausência de cloro residual e estagnação), é de se esperar que a concentração encontrada em água de chuva armazenada em cisternas seja elevada (SILVA, 2006).

Destaca-se, entretanto, que em 83,3\% das amostras analisadas, as cisternas têm um quantitativo maior de bactérias heterotróficas na água que o recomendado pelo Padrão de potabilidade estabelecido pela Portaria 518/04 MS.

\section{CONCLUSÕES}

O regime de distribuição de chuvas é irregular, assimétrico. No entanto, potencial de captação de água da chuva revela-se ser a principal alternativa hídrica para o semiárido nordestino.

Os tanques de pedras têm origem no processo de esfoliação na rocha, as quais possibilitam a percolação da água, proporcionando progressivamente o alargamento das fraturas.

Os indicadores da qualidade da água potável dos tanques de pedras, medidos com base nos parâmetros cor e turbidez, foram maiores que os valores estabelecidos pela Portaria do Mistério da Saúde (MS) no518/04, exceto o $\mathrm{pH}$ que encontra dentro da faixa recomendada.

A maioria da água (das cisternas) analisada está contaminada com bactérias heterotróficas totais e o uso de recipientes como baldes, latas de zinco e/ou alumínio, conectada com corda de náilon, são fatores de contaminação.

$\mathrm{O} \mathrm{pH}$ da água das cisternas é predominante básico e a dureza varia de mole a moderada. O desvio da água das primeiras chuvas e/ou o fechamento das cisternas, após a retirada da água, são fatores preponderantes e funcionam como barreiras sanitárias. 


\section{REFERÊNCIAS}

ALMEIDA, H. A. de, MOURA, M. S. B.; FARIAS, M. P. Social Water Technologies: Brazilian Experience of Coexistence and Development in the Semi -Arid Region of Paraiba. International Journal of Research in Geography (IJRG), v. 3, n. 2, p. 1-11, 2017

ALMEIDA, H. A. de, CABRAL JÚNIOR, J. B. Variabilidades sazonais e interdecadais da chuva nas microrregiões geográficas do estado da Paraíba. Revista Brasileira de Geografia Física, v.7, n.5 (Número Especial-VIWMCRHPE), p. 846-858, 2014.

ALMEIDA, H. A. de, VIRIATO, C. L. Qualidade de água armazenada em cisternas no cariri paraibano. In: Simpósio Brasileiro de Captação e Manejo de Água de Chuva, 9. Feira de Santana, BA, 2014, CD-R

ALMEIDA, H. A. de, CABRAL, L. N. Água e desenvolvimento sustentável na zona rural das microrregiões do agreste e curimataú da Paraíba. Revista de Geografia (UFPE), v.30, n.3, p. 82-97, 2013.

ALMEIDA, H. A. de, FREITAS, R. C., SILVA, L. Determinação de períodos secos e chuvosos em duas microrregiões da Paraíba através da técnica dos quantis. Revista de Geografia (UFPE), v. 30, n. 1, p. 217-232, 2013.

BRAGA, R. História da Comissão Científica de Exploração. Fortaleza: Imprensa Universitária do Ceará. 445 p, 1962.

BRASIL. MINISTÉRIO DA SAÚDE: Portaria No 518/2004. Estabelece os procedimentos e responsabilidades relativas ao controle e vigilância da qualidade da água para consumo humano e seu padrão de potabilidade, e dá outras providências. Disponível em: www.saude.gov.brBrasil, 2004

BRASILEIRO, W. Qualidade da Água e seus Tratamentos para fins de Abastecimento e Industrial. Departamento de Química IndustrialUEPB, Campina Grande, PB. 2009, p. 43

BRITO, L. T. de L.; SILVA, A. de S.; PORTO, E. R.; AMORIM, M. C. C. ; LEITE, W. de M. Cisternas Domiciliares: água para consumo humano. In: Brito, L. T. de L.; Moura, M. S. B. de; Gama, G. F. B. (org.). Potencialidades da água de chuva no Semiárido brasileiro. 1.ed. Petrolina: Embrapa Semiárido, 2007. v.1, p.81-101.

GNADLINGER, J. Tecnologias de captação e manejo de água de chuva em regiões semiáridas. In: Küster, Â.; Martí, J. F; Melchers, I (Org.). Tecnologias apropriadas para Terras Secas: manejo sustentável de recursos naturais em regiões semiáridas no Nordeste do Brasil. Fortaleza: Fundação Konrad Adenauer, GTS, 2006.

HAGEMANN, S. E. Avaliação da Qualidade da água da Chuva e da Viabilidade de sua Captação e Uso. Dissertação de mestrado. Universidade Federal de Santa Maria (UFSM, RS), 2009, 141p

LASSANCE JUNIOR, A. E.; PEDREIRA, J. S. "Tecnologias sociais e políticas públicas". In: Tecnologia social ñ uma estratégia para o desenvolvimento. Fundação Banco do Brasil, Rio de Janeiro, 2004.

LYE, D. J. Rooftop runoff as a source of contamination: a review. Science of the Total Environment, v. 407, p. 5429-5434, 2009

OLIVEIRA, G. C. S, NÓBREGA, R. S., ALMEIDA, H. A. de. Perfil socioambiental e estimativa do potencial para a captação de água da chuva em catolé de casinhas, PE. Revista de Geografia (UFPE), v.29, n.1, p. 75-90, 2012.

SINCLAIR, M.; LEDER, K.; CHAPMAN, H. Public Health Aspects of Rainwater Tanks in Urban Australia. Salisbury: Cooperative Research Centre for Water Quality and Treatment. 2005.

SILVA, S. A.; OLIVEIRA, R. Manual de Análises Físico-Químicas de Águas de Abastecimento e Residuárias. Campina Grande, Paraíba. 2001, p. 266.

SILVA, C. V. Qualidade da água de chuva para consumo humano armazenada em cisternas de placas. Estudo de caso: Araçuaí, MG. 2006. Dissertação de Mestrado. Universidade Federal de Minas Gerais, Minas Gerais, 2006

SOUZA, S. H. B., MONTENEGRO, S. M. G. L., SANTOS, S. M., PESSOA, S. G. S. Avaliação da Qualidade da Água e da Eficácia de Barreiras Sanitárias em Sistemas para Aproveitamento de Águas de Chuva. Revista Brasileira de Recursos Hídricos, v. 6 n.3, p. 81-93, 2011.

TAVARES, A. C. Aspectos físicos, químicos e microbiológicos da água armazenada em cisternas de comunidades rurais do semi-árido paraibano. Campina Grande: UFPB, 2009. 169p. Dissertação Mestrado.

VON SPERLING, M., Introdução á Qualidade das Águas e ao Tratamento de Esgotos. 2a Ed. Belo Horizonte: Departamento de Engenharia Sanitária e Ambiental (DESA) /Universidade Federal de Minas Gerais, 2005, 138p. 2005.

XAVIER, R. P. Influência de barreiras sanitárias na qualidade da água de chuva armazenada em cisternas no semiárido paraibano. Campina Grande: UFCG, 2010. 178p. Dissertação Mestrado 